- Technical Paper-

\title{
Raman Scattering for Hydrated Alkali Propionate Melt
}

\author{
Akihiko KAJINAMI,* Osamu SAKAI, and Shigehito DEKI \\ Department of Chemical Science \& Engineering, Faculty of Engineering, Kobe University (Rokko-dai, Nada, \\ Kobe 657-8501, Japan)
}

Received December 2, 1998 ; Accepted February 12, 1999

\begin{abstract}
Raman spectra were measured for the mixture of alkali metal propionates and water in the composition range of hydrate melt to highly concentrated solution. Band positions and band widths for the $\mathrm{C}_{1}-\mathrm{C}_{2}$ stretching, $\mathrm{C}-\mathrm{O}$ stretching in the propionate anion, and $\mathrm{O}-\mathrm{H}$ stretching bands in water molecule were investigated for various compositions and temperatures. The dependence of Raman bands on composition, cation, and temperature is discussed in view of ion-ion, ion-water, and water-water interactions, suggesting that the direct interaction between cation and anion increases with decreasing water content.
\end{abstract}

Key Words: Raman Scattering, Alkali Propionate, Hydrate Melt

\section{Introduction}

In hydrate melts or highly concentrated aqueous electrolyte solutions, which is involved in the boundary range between a molten salt and aqueous solution, ion-ion interactions affect the physico-chemical properties and the structure of liquids predominantly. In such a composition range, water cannot be regarded as continuous medium and thus the structure and interaction among dissolving species are very complicated in these solutions.

Alkali metal carboxylate-water systems are suitable for the investigation of various properties and structures in highly concentrated aqueous electrolyte solutions. These liquid systems are stable over a wide concentration range at relatively low temperature. Moreover, the carboxylate ion has both carboxylic and alkyl groups which yield hydrophilic and hydrophobic interactions in the aqueous solution, respectively. In the highly concentrated aqueous electrolyte solution, the hydrophilic, hydrophobic, and electrostatic interactions are considerably dependent on composition, cation, and temperature. The physico-chemical properties are closely related to these interactions.

Recently, numerous studies have been carried out on the hydration structure of ions and the interactions between nearest neighbors in electrolyte solutions. $\mathrm{X}$-ray ${ }^{1,2)}$ and neutron diffraction methods ${ }^{3)}$ and molecular vibrational spectroscopies such as Raman scattering ${ }^{4,5)}$ and infrared absorption ${ }^{6,7)}$ are useful for the investigation of the solute-solvent interaction. Especially Raman spectroscopy is suitable for the study of highly concentrated solutions since the visible light makes it possible to use a silica-glass or quartz as a sample tube. Furthermore, it is also possible to measure the depolarization by using of laser excitation, and the information of the symmetry of vibrational modes can be easily obtained.

In this study, alkali metal propionates-water systems were investigated. The variations of the ionion, ion-water, and water-water interactions with composition, cation, and temperature were discussed by Raman spectroscopy.

\section{Experimental}

\section{1 Preparation of samples}

Three kinds of alkali propionates; sodium propionate, potassium propionate, and rubidium propionate were used as electrolytes. Potassium and rubidium salts were prepared from a propionic acid and alkali hydroxide aqueous solutions by neutralization. Each solution was evaporated to eliminate excess acidic species and each propionate salt was obtained by heating at $473 \mathrm{~K}$ for several hours. These propionates, $\mathrm{C}_{2} \mathrm{H}_{5} \mathrm{COO} M(M=\mathrm{Na}, \mathrm{K}$, and $\mathrm{Rb})$, were dissolved in distilled water and filtered through a glass filter. The composition of samples was determined by gravimetry. In the following sections, the solution composition is designated as the parameter, $\mathrm{R}$, corresponding to the molar ratio of [water] to [salt].

\section{2 Raman scattering measurement}

Raman excitation was accomplished with $514.5 \mathrm{~nm}$ line of $\mathrm{Ar}^{+}$ion laser. The laser light was filtered through a pre-monochromator to suppress any natural emission of $\mathrm{Ar}^{+}$. The sample was injected in a glass tube (i.d. $4 \mathrm{~mm}$; o.d. $5 \mathrm{~mm}$ ). The laser beam was focused onto the sample tube center with power 
of $100 \mathrm{~mW}$. The scattered light was collected by a lens and introduced to a double monochromator of the Czerny-Tumer type (JOBIN YVON, U1000 system), and then detected by a photo multiplier (Hamamatsu, R943-02S) cooled by thermoelectric modules. Measurements of $\mathrm{I}_{/ /}$-spectra and $\mathrm{I}_{\perp}$-spectra were achieved by $90^{\circ}$ rotation of a polarizer. For the measurement of the polarized spectra, the direction of polarization was checked by obtaining the $\mathrm{I}_{/ /}$and $\mathrm{I}_{\perp}$ spectra of stretching mode for $\mathrm{CCl}_{4}$. Most of spectra were observed at an ambient temperature $(298 \mathrm{~K})$. Measurements at higher temperatures were performed by resistive heating of the sample holder. The temperature was detected with thermocouple (Type $\mathrm{K})$ and controlled at 313,328 , and $343 \mathrm{~K}$.

In order to confirm the band shift, all spectra obtained were corrected with the peak position of stretching bands, $459.3 \mathrm{~cm}^{-1}$, of $\mathrm{CCl}_{4}$ as a reference value. For deconvolution of the obtained spectrum, Gaussian or Lorentzian function was used, and component parameters of the functions such as peak frequency, half width, and relative intensity of bands were calculated with the personal computer.

\section{Results and Discussion}

A typical Raman spectrum of $\mathrm{C}_{2} \mathrm{H}_{5} \mathrm{COORb} \cdot 6 \mathrm{H}_{2} \mathrm{O}$ in the range of $0-4000 \mathrm{~cm}^{-1}$ is shown in Fig. 1. Those bands were assigned to the following vibrational modes according to the reference. ${ }^{8)}$ The intramolecular stretching modes such as $\mathrm{C}_{1}-\mathrm{C}_{2}$ stretching $\left(\nu=883 \mathrm{~cm}^{-1}\right)$, symmetric $\mathrm{C}-\mathrm{O}$ stretching $(\nu=$ $1415 \mathrm{~cm}^{-1}$ ), and $\mathrm{O}-\mathrm{H}$ stretching of water molecules were discussed. These bands are sensitive to the change of environments and shows relatively strong intensities.

\section{3. $1 \mathrm{C}_{1}-\mathrm{C}_{2}$ stretching mode}

Figure 2 shows the concentration dependence of the Raman band position of the $\mathrm{C}_{1}-\mathrm{C}_{2}$ stretching mode for three kinds of alkali metal propionates-water systems, $\mathrm{C}_{2} \mathrm{H}_{5} \mathrm{COO} M \cdot \mathrm{RH}_{2} \mathrm{O}(M=\mathrm{Na}, \mathrm{K}, \mathrm{Rb})$. These bands were shifted to the lower wavenumber range with the decrease of water content in the range of $R$

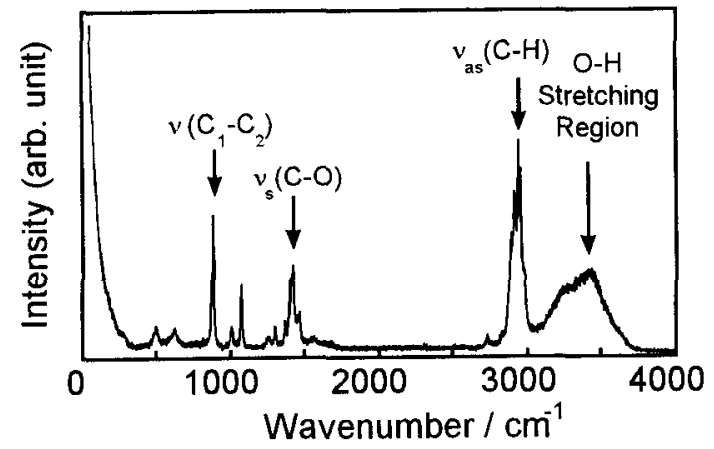

Fig. 1 Raman spectrum of $\mathrm{C}_{2} \mathrm{H}_{5} \mathrm{COORb} \cdot 6 \mathrm{H}_{2} \mathrm{O}$ melt. less than 15. In the less water range, the direct ionic interactions among cations and anions increase and yield the formations of ionic pair, which affect the reduced mass for molecular vibrations. It is suggested that the increase of the reduced mass by ion-pair formation causes the band shift to the lower wavenumber. In the range of $\mathrm{R}$ less than 15 , the peak frequency of the $\mathrm{C}_{1}-\mathrm{C}_{2}$ stretching band increases in the order of $\mathrm{Rb}^{+}<\mathrm{K}^{+}<\mathrm{Na}^{+}$. The differences of band position among three systems with three kinds of cation are also due to the difference of the mass and size of cation. Therefore, the Raman band for the $\mathrm{C}_{2} \mathrm{H}_{5} \mathrm{COORb}-\mathrm{H}_{2} \mathrm{O}$ system containing heavy $\mathrm{Rb}^{+}$ cation shows the lowest wavenumber.

The concentration dependence of the band positions at various temperatures is shown in Fig. 3(A) for sodium propionate aqueous solution, and in Fig. 3(B) for rubidium propionate aqueous solution. It is obvious that $\mathrm{C}_{1}-\mathrm{C}_{2}$ stretching mode shows a shift to the lower wavenumber with increasing temperature for

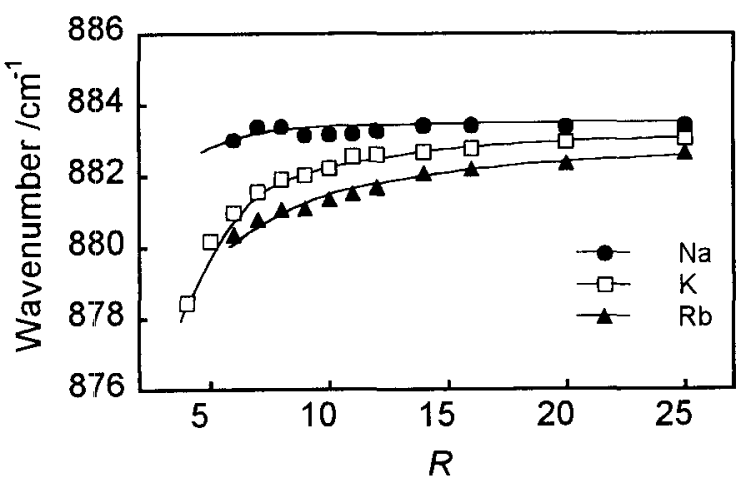

Fig. 2 Concentration dependence of $\nu\left(\mathrm{C}_{1}-\mathrm{C}_{2}\right)$ band position in $\mathrm{C}_{2} \mathrm{H}_{5} \mathrm{COO} M \cdot \mathrm{RH}_{2} \mathrm{O}(M=\mathrm{Na}, \mathrm{K}, \mathrm{Rb})$ melts.

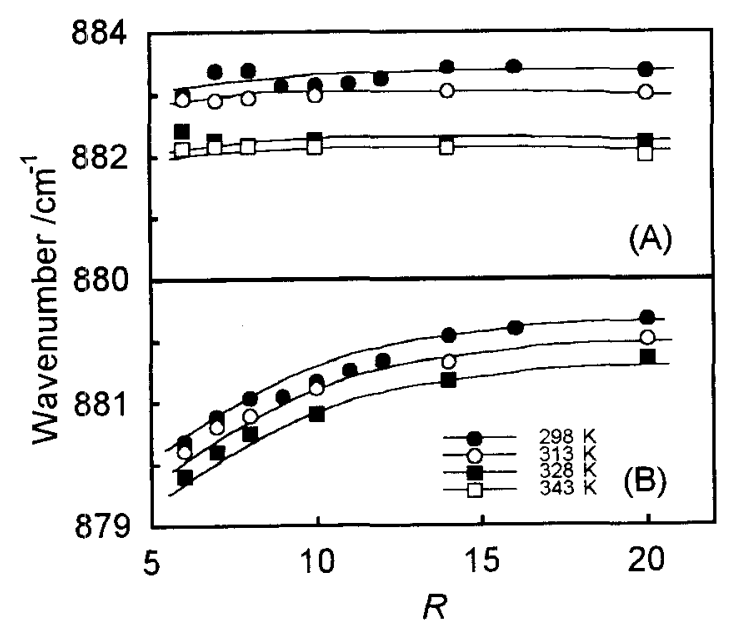

Fig. 3 Concentration dependence of $\nu\left(\mathrm{C}_{1}-\mathrm{C}_{2}\right)$ band position for hydrated alkali propionate melts at various temperatures. (A) : $\mathrm{C}_{2} \mathrm{H}_{5} \mathrm{COONa} \cdot \mathrm{RH}_{2} \mathrm{O}$ and (B) : $\mathrm{C}_{2} \mathrm{H}_{5}$ $\mathrm{COORb} \cdot \mathrm{RH}_{2} \mathrm{O}$. 
rubidium propionate. The temperature dependence suggests that water molecules around ions easily dehydrate at high temperature, ${ }^{9)}$ and that the strong interaction between cation and anion leads to shift the Raman band to the lower wavenumber.

\section{2 C-O symmetric stretching mode}

Raman spectrum of $\mathrm{C}_{2} \mathrm{H}_{5} \mathrm{COORb} \cdot 20 \mathrm{H}_{2} \mathrm{O}$ system in the range of $1320-1550 \mathrm{~cm}^{-1}$ is shown in Fig. 4. The band at about $1420 \mathrm{~cm}^{-1}$ is assigned to a C-O symmetric stretching mode. The band is overlapped with other bands such as $\mathrm{CH}_{3}$-deformation modes (about $1370 \mathrm{~cm}^{-1}$ ). Therefore the band position and the intensity of the $\mathrm{C}-\mathrm{O}$ symmetric stretching mode are evaluated by the deconvolution with four components at maximum as shown in Fig. 4.

Figure 5 shows the concentration dependence of the band positions for $\mathrm{C}_{2} \mathrm{H}_{5} \mathrm{COO} M \cdot \mathrm{RH}_{2} \mathrm{O}(M=\mathrm{Na}, \mathrm{K}$, $\mathrm{Rb})$ near $1415 \mathrm{~cm}^{-1}$. Those bands shifted to the higher wavenumber with the decrease of water content on the contrary to that of $\mathrm{C}_{1}-\mathrm{C}_{2}$ stretching mode. It is well known that a stretching mode peak shifts to the lower frequency owing to hydrogen bond formation. ${ }^{10)}$ The C-O stretching mode shows a shift to the higher wavenumber with decreasing water content since the carboxylate anion interacts with alkali cation rather than water molecules in the high con-

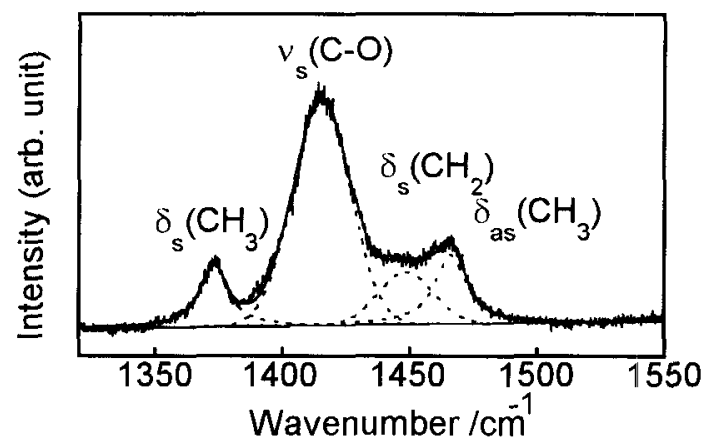

Fig. 4 The results of curve fitting for $\nu_{\mathrm{s}}(\mathrm{C}-\mathrm{O})$ band in $\mathrm{C}_{2}$ $\mathrm{H}_{5} \mathrm{COONa} \cdot 20 \mathrm{H}_{2} \mathrm{O}$ melt.

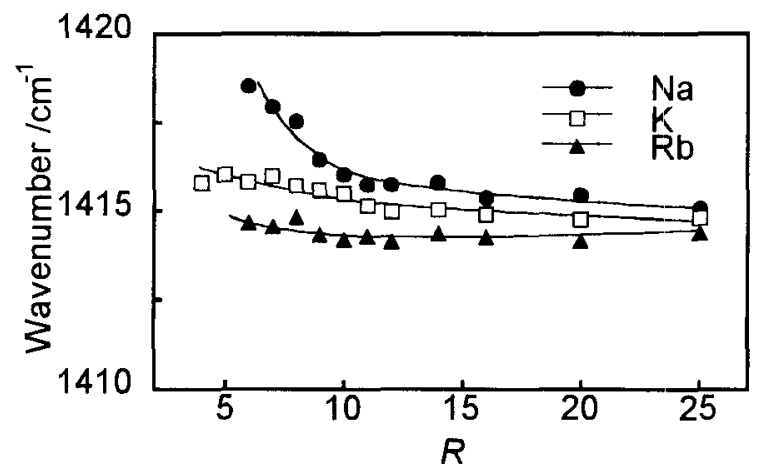

Fig. 5 Concentration dependence of $\nu_{\mathrm{S}}(\mathrm{C}-\mathrm{O})$ band position in $\mathrm{C}_{2} \mathrm{H}_{5} \mathrm{COOM} \cdot \mathrm{RH}_{2} \mathrm{O}(M=\mathrm{Na}, \mathrm{K}, \mathrm{Rb})$ melts. centration region. The difference among three kinds of cation systems is due to the mass and size of cation similar to the case of the $\mathrm{C}_{1}-\mathrm{C}_{2}$ stretching mode.

Figure 6 shows the concentration dependence of the intensity ratio of the $\mathrm{C}-\mathrm{O}$ symmetric stretching band to the symmetric $\mathrm{CH}_{3}$-deformation band at $\mathrm{ca} .1370$ $\mathrm{cm}^{-1}$. As the $\mathrm{CH}_{3}$-deformation mode is not sensitive to the change of surroundings, the intensity ratio is used for discussion of the intensity of C-O symmetric stretching band. It is supposed that the direct interaction between cations and anions affects the polarizability variation for the $\mathrm{C}-\mathrm{O}$ band and increases the intensity. The difference in three kinds of cation systems is due to their charge density change.

The band position at various temperatures was also investigated for sodium propionate-water systems. The $\mathrm{C}-\mathrm{O}$ symmetric stretching band appears at the lower frequency region with the increase of temperature. This behavior is induced by the dehydration of the ions and the remaining strong ionic interaction at the high temperature region.

3. 3 O-H stretching mode for water molecule in alkali metal propionate-water systems

Figure 7 shows the Raman spectrum in the range from 3000 to $3800 \mathrm{~cm}^{-1}$ for $\mathrm{C}_{2} \mathrm{H}_{5} \mathrm{COONa} \cdot 20 \mathrm{H}_{2} \mathrm{O}$ melt.

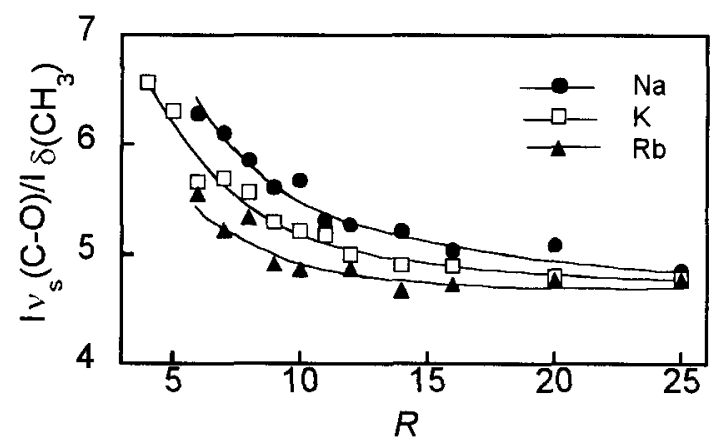

Fig. 6 Concentration dependence of intensity ratio $I_{v_{s}(\mathrm{C}-\mathrm{O})} / I_{s\left(\mathrm{CH}_{3}\right)}$ in $\mathrm{C}_{2} \mathrm{H}_{5} \mathrm{COO} M \cdot \mathrm{RH}_{2} \mathrm{O}(M=\mathrm{Na}, \mathrm{K}, \mathrm{Rb})$ melts.

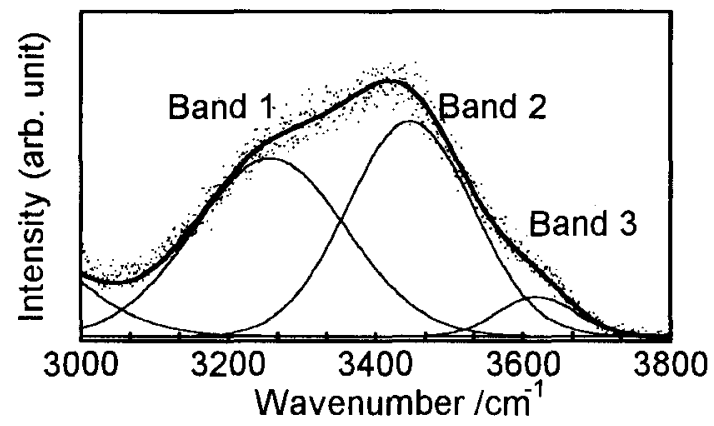

Fig. 7 The results of curve fitting for $\mathrm{O}-\mathrm{H}$ stretching region in $\mathrm{C}_{2} \mathrm{H}_{5} \mathrm{COONa} \cdot 20 \mathrm{H}_{2} \mathrm{O}$ melt. 
The $\mathrm{O}-\mathrm{H}$ stretching band is deconvoluted to Band 1 , Band 2, and Band 3 as shown in Fig. 7 by referring to the previous researches for pure water. ${ }^{11-13)}$ From the temperature dependence of pure water and the polarization ratio measurements, the Band 1 is assigned to the hydrogen-bonded $\mathrm{O}-\mathrm{H}$ stretching band in the icelike structure. The Band 2, which is the less symmetrical mode than Band 1, is assumed to be the hydrogen-bonded $\mathrm{O}-\mathrm{H}$ stretching in the broken icelike structure. The Band 3 is assigned to the nonhydrogen bonded $\mathrm{O}-\mathrm{H}$ stretching one.

The concentration dependence of Raman band positions and half widths of Band 1 are shown in Fig. $8(\mathrm{~A})$ and (B), respectively. It is confirmed that the Raman band positions of Band 1 shift to the higher frequencies and the half widths increase with the decrease of water content. It is obvious that the three kinds of cation systems show same concentration dependence. These changes are similar to the results of measurement at elevated temperature for pure water, and the destruction of the hydrogen-bond networks by the existence of ions has been suggested. ${ }^{14)}$

Figure 9 shows variation of the relative intensity of the Bands 1, 2 and 3 to the total integrated intensity of the $\mathrm{O}-\mathrm{H}$ stretching bands with the water content in the $\mathrm{C}_{2} \mathrm{H}_{5} \mathrm{COONa} \cdot \mathrm{RH}_{2} \mathrm{O}$ melts. It is found that the relative intensities of Band 1 and Band 3 decreases with the decrease of water content, while the intensity of Band 2 increases, indicating that the ice-like network structure and nonhydrogen-bonded water decrease and the broken network structure increases with the decrease of water content.

Figure 10 shows the concentration dependence of

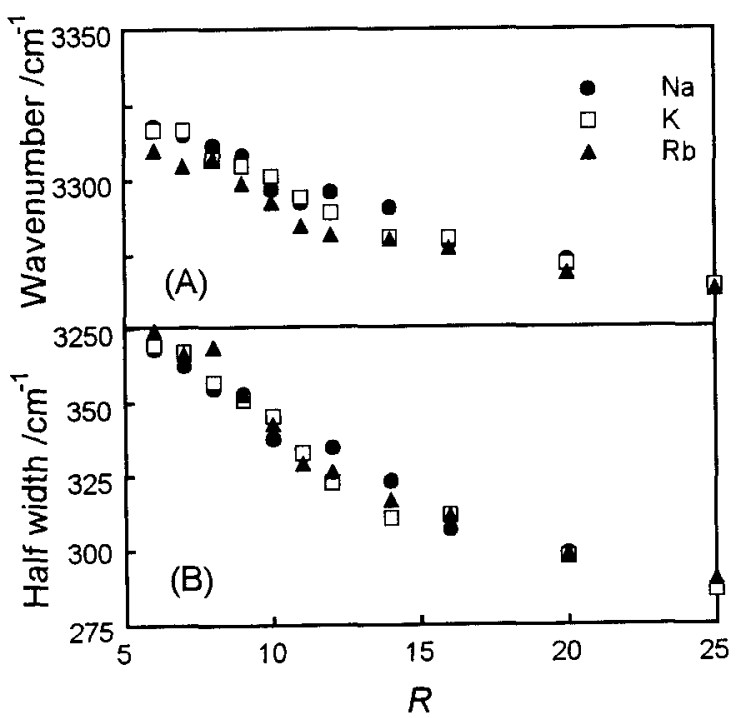

Fig. 8 Concentration dependence of $(A)$ the band position and $(\mathrm{B})$ the half width of Band 1 of $\mathrm{OH}$ stretching mode in $\mathrm{C}_{2} \mathrm{H}_{5} \mathrm{COO} M \cdot \mathrm{RH}_{2} \mathrm{O}(M=\mathrm{Na}, \mathrm{K}, \mathrm{Rb})$ melts.

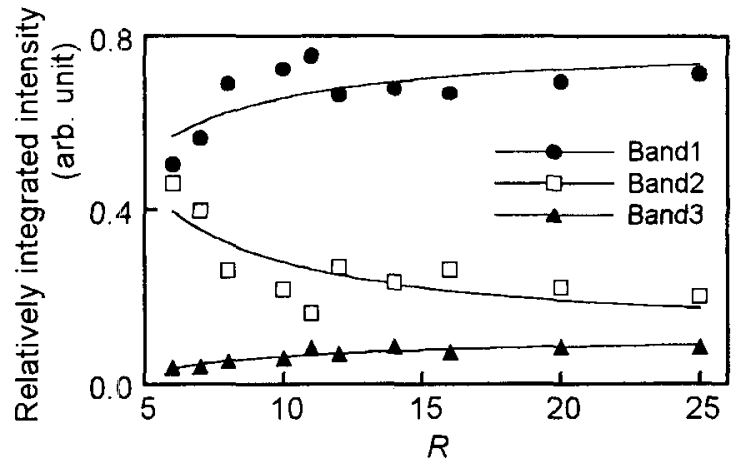

Fig. 9 Concentration dependence of relatively integrated intensities for $\mathrm{O}-\mathrm{H}$ stretching bands in $\mathrm{C}_{2} \mathrm{H}_{5} \mathrm{COONa} \cdot \mathrm{RH}_{2}$ O melts.

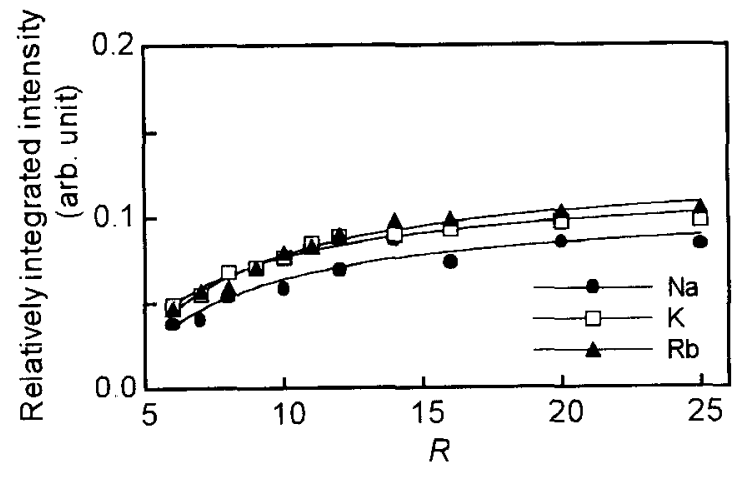

Fig. 10 Concentration dependence of relatively integrated intensity for $\mathrm{O}-\mathrm{H}$ stretching band (Band 3) in $\mathrm{C}_{2} \mathrm{H}_{5}$ $\mathrm{COO} M \cdot \mathrm{RH}_{2} \mathrm{O}(M=\mathrm{Na}, \mathrm{K}, \mathrm{Rb})$ melts.

integrated intensity of Band 3 for $\mathrm{C}_{2} \mathrm{H}_{5} \mathrm{COOM} \cdot \mathrm{RH}_{2} \mathrm{O}$ $(M=\mathrm{Na}, \mathrm{K}, \mathrm{Rb})$ melts. The three kinds of alkali systems show the similar variations with the water content. The integrated intensity with the same water content increases in the order of $\mathrm{Na}^{+}<\mathrm{K}^{+}<$ $\mathrm{Rb}^{+}$. The cation with large charge density seems to be difficult to make water molecules unbound. The difference is distinguishable in the high water concentration range where cations have the less interaction with carboxylate anions.

The relatively integrated intensity of Band 3 increases at the higher temperatures, which shows that the hydrogen bonding is broken and the free water increases at the high temperature in agreement with the result of Band 1.

\section{Conclusion}

Band positions in Raman scattering spectra such as the $\mathrm{C}_{1}-\mathrm{C}_{2}$ stretching and the $\mathrm{C}-\mathrm{O}$ symmetric stretching in alkali metal propionates and water systems depend strongly on the water content, cation, and temperature. These behaviors are caused by the increase of 
the cation-anion interaction.

It is confirmed that the hydrogen bond network of water molecules is broken in the less water containing region and at the high temperatures from the analyses of $\mathrm{O}-\mathrm{H}$ stretching mode, and the nonhydrogen-bonded component in the Raman band decreases with the decrease of water content.

\section{Acknowledgements}

This study was supported by the Proposal-Based New Industry Creative Type Technology R \& D Promotion Program from the New Energy and Industrial Technology Development Organization (NEDO) of Japan.

We thank "Center for instrumentation analysis" of Kobe University for our using Raman spectrometer.

\section{References}

1) T. Takamaru, M. Ihara, T. Yamaguchi, and H. Wakita, Z. Naturforsch., 47a, 485 (1992).

2) R. Caminiti, P. Cucca, M. Monduzzi, and G. Saba, J. Chem. Phys., 81, 543 (1984).

3) K. Ichikawa, S. Kotani, M. Izumi, and T. Yamanaka,
Mol. Phys., 77, 677 (1992).

4) A. T. G. Lemley and R. A. Plane, J. Chem. Phys., 57, 1648 (1972).

5) D. E. Irish and A. R. Davis, Can. J. Chem., 46, 943 (1963).

6) J. E. Tackett, Appl. Spectrosc., 43, 483 (1989).

7) H. Kimura and J. Kai, Denki Kagaku, (presently Electrochemistry), 53, 550 (1985).

8) R. I. Bickley, H. G. M. Edwards, R. Gustar, and S. J, Rose, J. Mol. Structure, 248, 237 (1991).

9) J. L. Fulton, D. M, Pfund, S. L. Wallen, M. Newville, E. A. Stem, and Y. Ma, J. Chem. Phys., 105, 2161 (1996).

10) G. C. Pimentel and A. L. Mclellan, The Hydrogen Bond, W. H. Freeman and Company, San Francisco and London, p. 67 (1959).

11) W. B. Monosmith and G. E. Walrafen, J. Chem. Phys., 81, 669 (1984).

12) G. E. Walrafen, Water, A Comprehensive Treatise, (Ed. F. Franks), Vol. 1, Plenum Press, New York and London, p. 151 (1972).

13) D. Risenberg and W. Kauzman, The Structure and Properties of Water, Oxford at the Clarendon Press, London (1969).

14) G. E. Walrafen, J. Chem. Phys., 52, 4176 (1969). 